\title{
PRESENTACIÓN
}

\section{El retorno del PRI}

\author{
Alberto Aziz Nassif
}

I

$\int$ n este número la revista Desacatos presenta un conjunto de textos sobre el proceso electoral de 2012. Por segunda ocasión incursiona en el tema de la política electoral, con el objetivo de hacer un seguimiento a un proceso que concentró la atención nacional antes y después de la jornada electoral. En nuestro país los comicios no han dejado de ocupar y preocupar a la clase política y, en menor medida, a la ciudadanía. El acento ha sido marcado, en buena parte, por la enorme desconfianza que se gestó en la época del partido hegemónico, porque cuando las oposiciones empezaron a ser competitivas la respuesta oficial fue el fraude en las urnas y la mezcla del gobierno con su partido, por eso se le llamó "partido de Estado". Esos tiempos que ya se han ido todavía dejan humores que alimentan la desconfianza y convierten a las elecciones mexicanas en un episodio que, casi siempre, genera insatisfacción y despierta algún tipo de sospecha. 2012 no es una excepción a esta suerte de maldición con la que carga la vida política del país.
En el número 24 de Desacatos, hace seis años, presentamos un conjunto de textos que daba testimonio del proceso electoral de 2006. Ahora nos propusimos no sólo hacer un recuento de qué pasó un sexenio después, sino tratar de entender las diferencias y semejanzas, las novedades y las repeticiones, los avances y pendientes de este proceso que ha tenido como objetivo construir elecciones institucionalizadas, es decir, democráticas, para que los comicios se desarrollen de acuerdo con el marco legal y los resultados se generen en un clima de confianza y legalidad, como la vía para lograr un acceso legítimo al poder. Hace seis años referimos unas elecciones que se caracterizaron por el conflicto y la polarización, en esta ocasión no fue así. No dejó de haber impugnación y conflicto, pero el grado fue mucho menor. La polarización también disminuyó y los acontecimientos se procesaron dentro de los canales institucionales. En buena medida la gran diferencia en los resultados entre primero y segundo lugares - de $0.56 \%$ a más de 6 puntos porcentuales- propició un litigio de menor intensidad, en el que era muy improbable un cambio en el resultado.

\section{The Return of the PRI}

Alberto Aziz Nassif: Centro de Investigaciones y Estudios Superiores en Antropología Social-Distrito Federal, México aziz@ciesas.edu.mx 
Además, varias de las piezas del conflicto de 2006 tuvieron respuesta con la reforma electoral de 2007-2008, como el nuevo modelo de regulación de acceso a los medios masivos en tiempos del Estado, la prohibición de compra de tiempos para todos los actores o las posibilidades de un recuento de votos amplio para despejar dudas. Las elecciones de 2012 no serán recordadas como las de un conflicto irresoluble, sino como las que pusieron a prueba las nuevas reglas electorales. Tal vez serán las elecciones del regreso del PRI a Los Pinos, las del movimiento estudiantil \#YoSoy132 o las elecciones del clientelismo. Independientemente de cómo quedarán en la memoria, las elecciones de 2012 fueron un acontecimiento complejo que puso de manifiesto diversas dinámicas sobre el estado en el que se encuentra el país.
II

Es importante ubicar el contexto electoral, sobre todo a partir de algunos resultados de las dos administraciones panistas y, en particular, de la segunda. Después de un sexenio en que la violencia cambió el rostro de muchas regiones del país - los asesinatos se incrementaron a niveles pocas veces vistos, al grado de considerar a la estrategia de "guerra" en contra del crimen organizado y el narcotráfico como uno de los conflictos más relevantes del mundo-, la sociedad llegó a las elecciones con una demanda: disminuir la violencia. El Movimiento Social por la Paz con Justicia y Dignidad fue un actor relevante que logró darle visibilidad a la tragedia humana que ha vivido México en estos años.

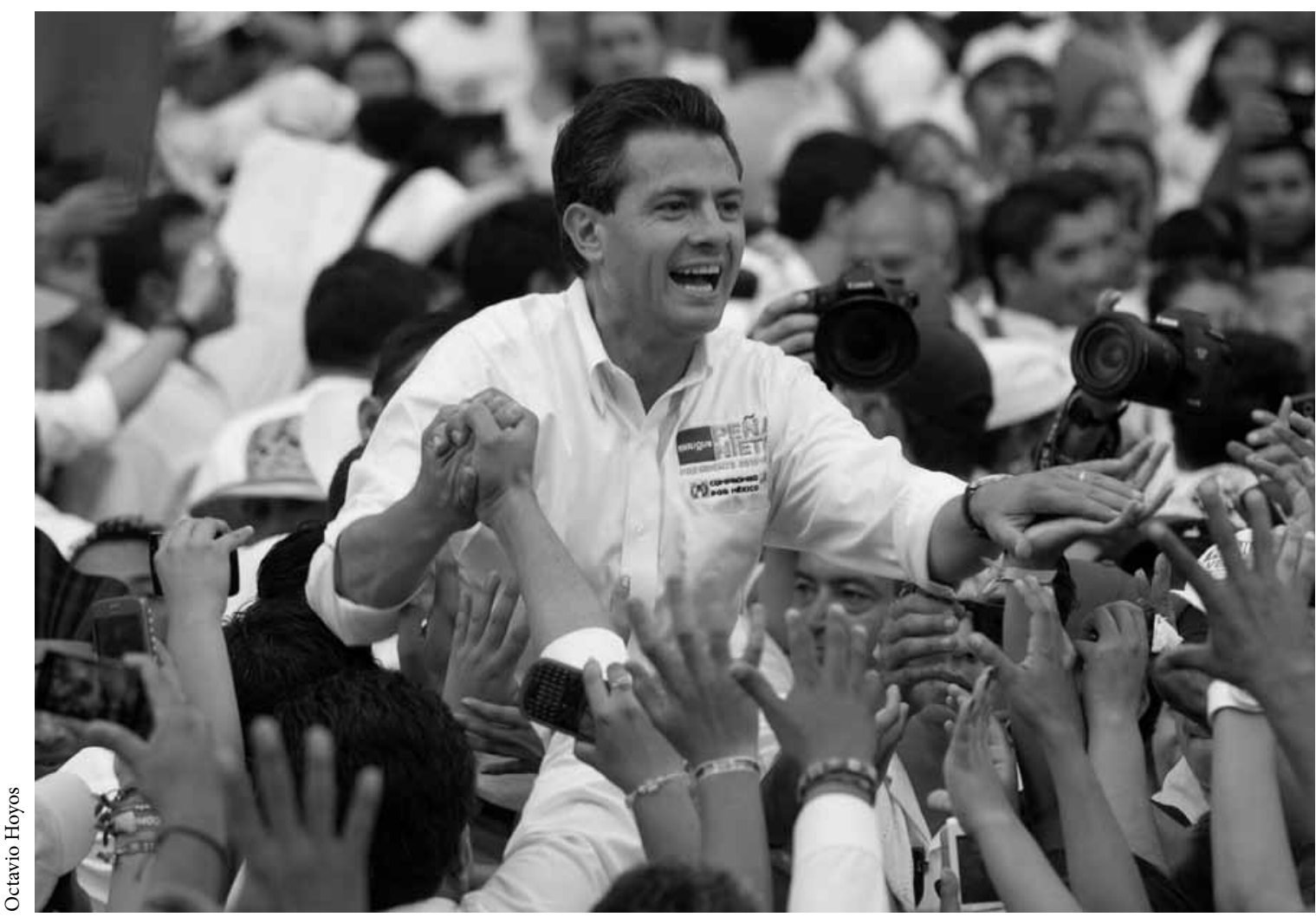

Acto de campaña del candidato del Partido de la Revolución Democrática, Enrique Peña Nieto, en Chiapas, 30 de mayo de 2012. 
La estrategia de gobierno que se empecinó en ir contra el crimen no tuvo un diagnóstico claro de la situación. Uno de los argumentos era que el crimen había penetrado al Estado, la publicidad que se hacía en spots decía que la lucha era para evitar que las drogas llegaran al consumo de los jóvenes. Fueron versiones de una narrativa que se cae parte por parte: si había complicidad, no se llegó a un recambio o a tener procesos que dieran cuenta de esa colusión, no se sabía cuáles eran los objetivos - quizá por ello la percepción ciudadana era que el Estado perdía la guerra-, los índices de consumo de droga aumentaron y todo a costa de una grave descomposición y un incremento de la violencia. Este conflicto acompañó a las elecciones como un referente que sí influyó en el proceso y en la derrota del partido gobernante, que cayó al tercer sitio en las preferencias electorales.

Después de dos sexenios de alternancia panista las elecciones de 2012 fueron también una evaluación retrospectiva. Si el panismo se desplomó -además de los errores y limitaciones de su candidata, Josefina Vázquez Mota-, fue en buena medida por las promesas incumplidas, por haber navegado entre los intereses con un acomodo que poco se diferenció del PRI. En temas sustantivos como la pobreza tampoco hubo cambios importantes y se incrementó, en parte también por la crisis internacional de 2008-2009, pero sobre todo por la estrategia de los programas sociales que hablan de combatir la pobreza cuando en realidad lo que hacen es administrarla. La corrupción no se abatió, por el contrario: con cifras de finales de 2011, el Índice de Transparencia Internacional muestra que México es percibido como uno de los países con mayores niveles de corrupción, ocupa el lugar 100 de 180, en América Latina es el número 20 de 34 y en la Organización para la Cooperación y el Desarrollo Económicos está en el último lugar, el 34. La promesa de la honestidad queda como saldo en contra. Las alianzas de los gobiernos panistas con actores desprestigiados del sindicalismo, el acomodo con los intereses monopólicos, la desorganización del

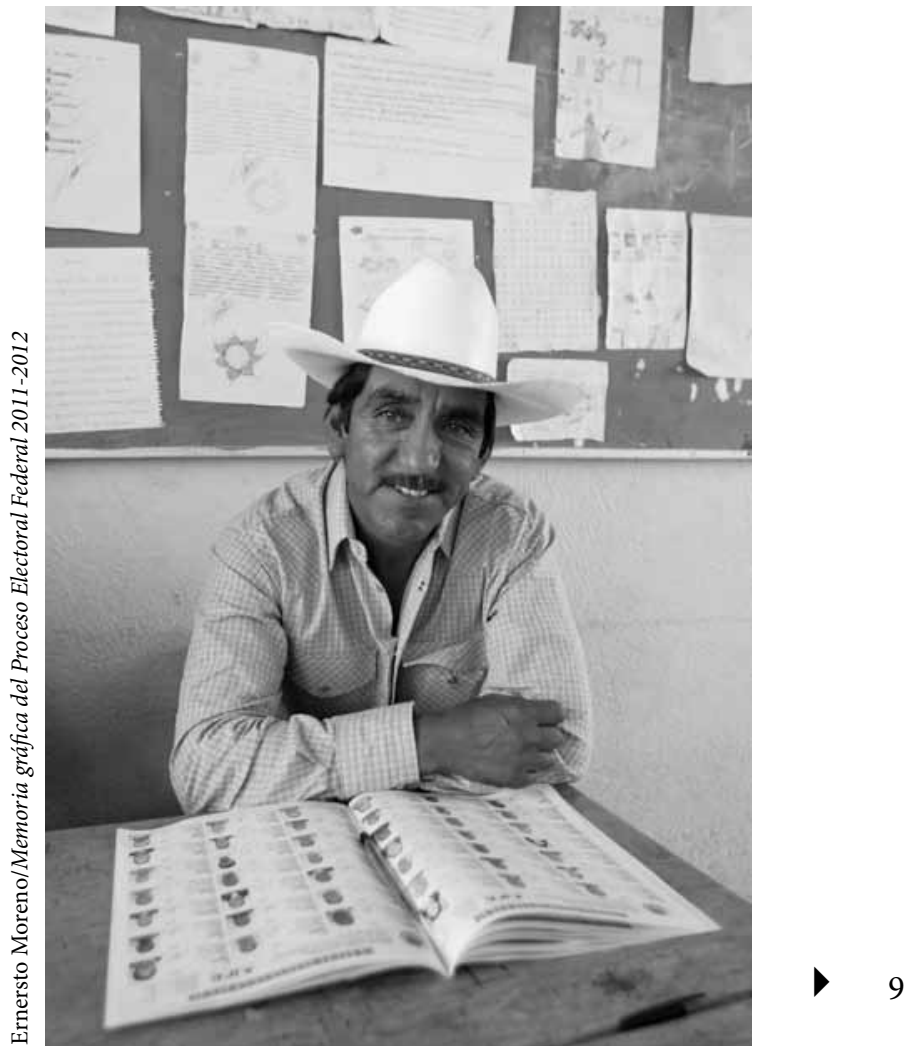

Zacatecas, Zacatecas, 2012.

Estado no sólo frente al crimen, sino respecto de una débil regulación de intereses, y el vaciamiento democrático que ha llevado al país a ubicarse en los últimos lugares de satisfacción y apoyo democráticos, de acuerdo con las cifras del Latinobarómetro, son también una muestra del conjunto de problemas que afectan al país. En México sólo 22\% de la población opina que se gobierna por el bien del pueblo, cuando en Brasil la cifra es de 52\%, en Uruguay de $62 \%$ y el promedio en América Latina es de 35\%. El apoyo a la democracia está en $40 \%$, bajó nueve puntos porcentuales de 2010 a 2011, sólo arriba de Guatemala. A ello sumamos el bajo crecimiento económico y la rigidez de lo que se ha llamado el modelo de "estancamiento estabilizador" en el que está aprisionado México, por lo que $76 \%$ de la población considera que el país está estancado o en retroceso. 
Todas estas razones son suficientes para que las elecciones de 2012 se plantearan dentro de una narrativa plebiscitaria de más de lo mismo o un cambio. Si analizamos la jerarquía de los votos, podemos ver que una mayoría, los votos del primero y el segundo lugares, expresó la necesidad de un cambio en dos sentidos: uno hacia el regreso del PRI, el viejo partido gobernante, otra derecha diferente a la panista, y el otro de la derecha hacia la izquierda. Con estos referentes, entre muchos otros, México llegó a su cita sexenal para participar en una nueva sucesión presidencial. Las elecciones federales han sido un momento de decisiones y de definiciones en las últimas décadas y esta vez no fue una excepción.

\section{III}

Sin duda, el objeto electoral se ha convertido cada vez más en un espacio de investigación complejo, en el que ya hemos dejado atrás la certeza de las leyes que algunos de los pioneros esbozaron para darle un carácter de cientificidad a estos estudios. Estas leyes, que planteaban la repetición invariable de resultados y conductas, encontraron tantas excepciones que dejaron de tener carácter de ley. También podemos indicar que los factores de la causalidad simple -si $x$, luego $y$-se han visto en la necesidad de acudir a variables múltiples y a análisis de tantas excepciones que también han tenido que recurrir a modelos de alcance más limitado, es decir, al estudio de singularidades en los que la generalización se relativiza o se acota. En los estudios electorales del caso mexicano hay otra circunstancia recurrente -al menos en las últimas cinco sucesiones presidenciales: 1988, 1994, 2000, 2006 y 2012-, aunque con particularidades en cada caso: la tensión entre el modelo de regulación electoral y la insatisfacción con su resultado, quizá con la única excepción de 2000.

Otra de las variables que ha aparecido puntual en las elecciones mexicanas es la tensión en una competencia que se expresa de forma plebiscitaria, lo cual ha subido los niveles de competencia, pero curiosamente no ha incrementado los niveles de participación. Desde el registro de 1994, cuando hubo una participación muy elevada y cercana a $80 \%$ del padrón, en los siguientes procesos se ha registrado un decremento. En 2000, 2006 y en 2012 se pudo observar de nuevo un pequeño crecimiento. Así que la competencia que se expresa en una incertidumbre sobre el ganador no ha tenido un comportamiento uniforme para determinar si hay incremento en la participación.

En el balance de 2012 ponemos a discusión algunas hipótesis, como la modificación de un triunfo de Enrique Peña Nieto que se construyó como inevitable desde las imágenes de la televisión, el registro de las encuestas y, lo menos visible, la coalición de intereses que acompañaron la candidatura del Partido Revolucionario Institucional (PRI). El desgaste del partido gobernante, con saldos muy críticos como hemos apuntado, tenía una perspectiva complicada para refrendar un tercer periodo consecutivo de gobierno. Por su parte, la izquierda aparecía con un desprestigio considerable, como resultado de las acciones que tomó en la crisis poselectoral de 2006 y en las divisiones internas del Partido de la Revolución Democrática (PRD), por lo que el candidato Andrés Manuel López Obrador inició la competencia con un gran déficit. La aparición del movimiento estudiantil a la mitad de la campaña con un fuerte rechazo al statu quo, representado por el PRI y el Partido Acción Nacional (PAN), abrió una variable que afectó la dinámica de un triunfo inevitable del candidato tricolor. Al aumentar la competencia, se intensificó la incertidumbre y, en esta ocasión, subió el nivel de participación.

\section{IV}

Los trabajos que integran la sección "Saberes y razones" forman las piezas de un rompecabezas que tiene como objetivo mostrar algunas de las partes más sobresalientes de la sucesión presidencial de 2012. Jorge Alonso hace un detallado análisis del movimiento 
estudiantil \#YoSoy132 en sus primeros cinco meses de vida mediante una caracterización de sus facetas, que inician con una de enojo, a la que sigue una serie de reacomodos y rupturas, para dar paso a una fase de denuncia de las condiciones de la elección en dos niveles: por una parte, en la denuncia de la concentración mediática y, por otra, en la construcción de la candidatura del PRI que implicaba un regreso al pasado, para llegar a una lógica diversa a la del sistema de dominación. El artículo de Alberto Aziz Nassif presenta un conjunto de paradojas, entendidas como contradicciones y decisiones no satisfactorias, con el fin de exponer de qué manera esta elección dejó dudas sobre la calidad y la legitimidad democráticas. Se analizan las paradojas de una nostalgia por el pasado, referida al regreso del PRI, la alteración en las condiciones de equidad en el uso de medios - en especial de la televisión a favor del PRI- en las fases previas a la campaña electoral, el modelo mediático y la dominancia de los spots por encima de los debates, los cambios en la estrategia por los imprevistos de la campaña, las herencias de los candidatos, la modificación del escenario por el movimiento estudiantil, las expectativas de un resultado incierto y los errores de las encuestas.

Ana Mercedes Saiz Valenzuela sigue una ruta similar para explicar que hay dos caras en la elección desde el mirador institucional de lo que sucedió dentro del IFE a partir de dos pruebas, que fueron desafíos: el recuento de los votos, un problema importante en 2006, y la fiscalización. Trabaja el tema del uso político de las normas electorales y cómo

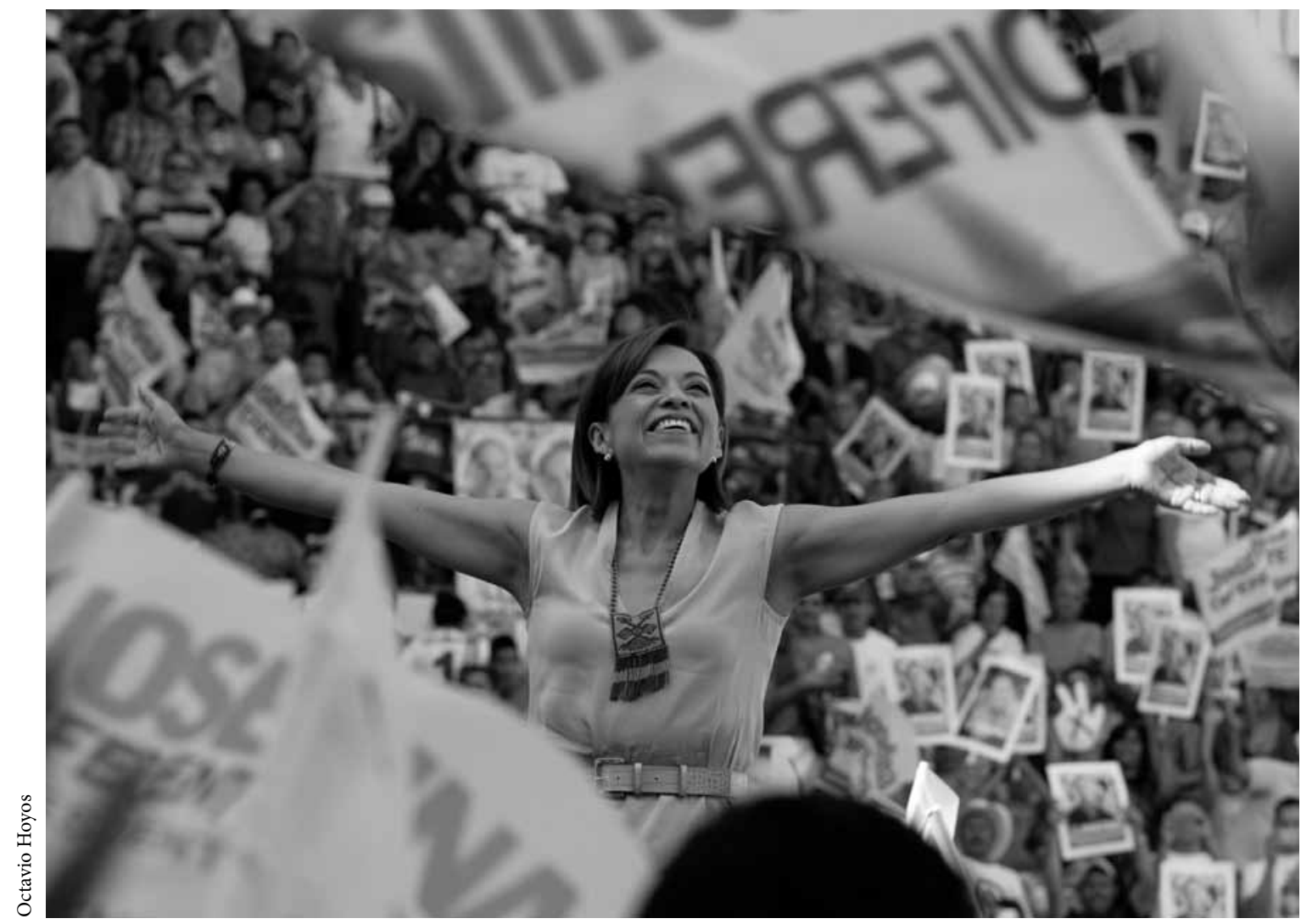

Acto de campaña de Josefina Vázquez Mota, candidata del Partido Acción Nacional a la presidencia de México, Aguascalientes, Aguascalientes, 2012. 


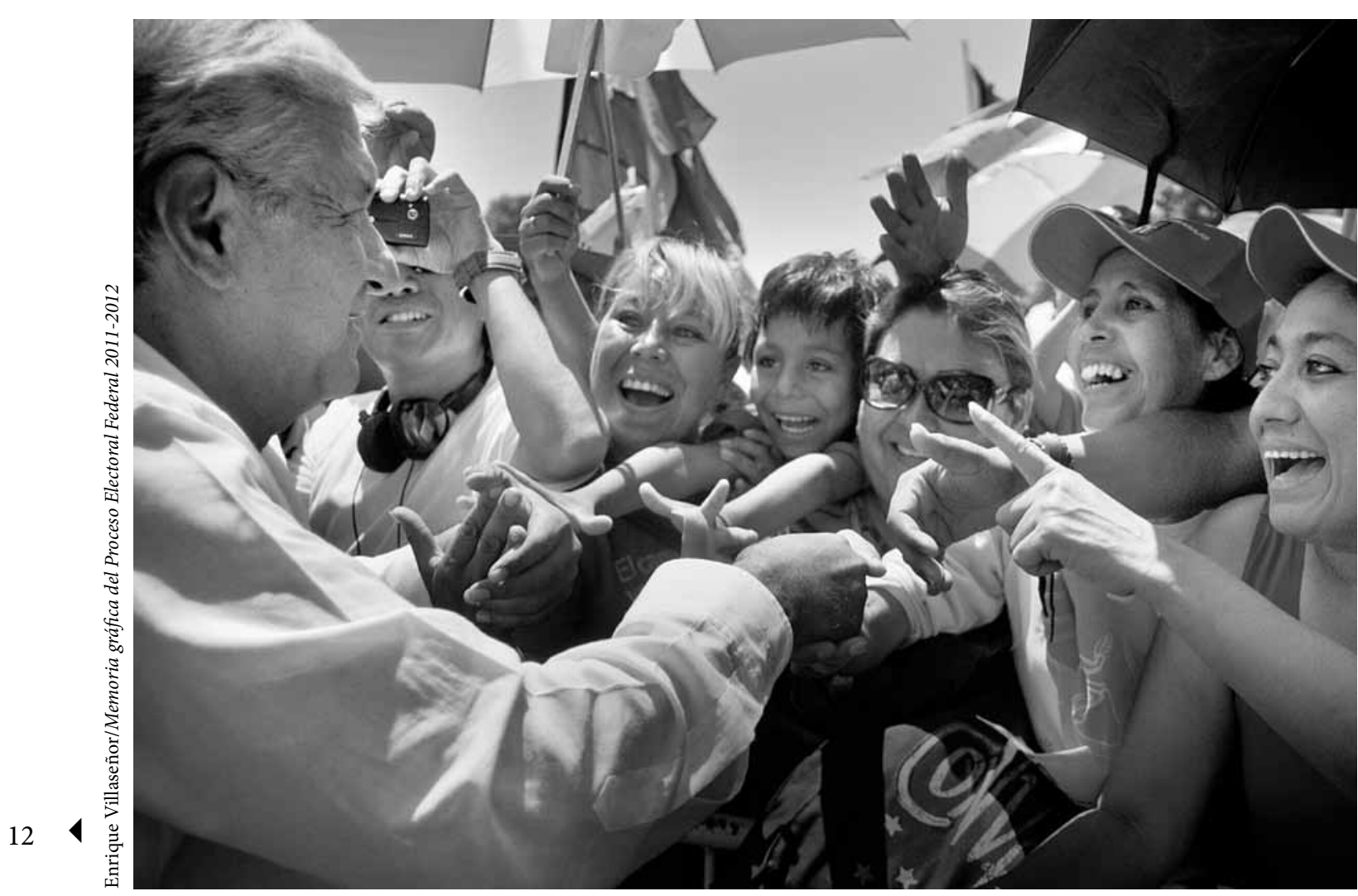

Andrés Manuel López Obrador, candidato de la Coalición Movimiento Progresista a la presidencia de la república en Durango, Durango, 2012.

pueden manipularse en función de la estrategia litigiosa de los actores. De suerte que lo que se gane en estas estrategias se pierde en la certeza que puede tener la ciudadanía. El otro desafío es la fiscalización, procedimiento diseñado para hacer el menor daño posible a los partidos, que se benefician en la lógica, los tiempos y las sanciones. Jesús Cantú revisa el modelo mediático a partir de un planteamiento sobre el pluralismo y de un seguimiento a los dos principales noticieros de la televisión y a tres diarios del Distrito Federal: El Universal, Reforma y La Jornada. En el análisis se explica por qué la concentración mediática afecta de manera directa el pluralismo externo y de qué forma esta situación, salvo la excepción de la ciudad de México, en donde sí hay un pluralismo externo sobre todo por la prensa escrita, en el resto del país el duopolio televisivo es un obstáculo para tener comicios informados. De alguna manera, Cantú demuestra la tesis del movimiento estudiantil sobre la concentración mediática, como se podrá ver en el texto de Jorge Alonso. En el artículo se documenta que los votantes que se informan por la televisión se inclinaron más por el candidato del PRI, y en cambio los de internet prefirieron al candidato de la izquierda. Los medios son una asignatura pendiente para una reforma que democratice este importante espacio de la vida pública, que se encuentra monopolizado.

El trabajo de José Antonio Crespo se centra en un análisis del voto de la izquierda. Se exponen las razones por las que esta opción no ha podido ganar la presidencia de la república, a pesar de que hubiera sido una rotación del poder antes de que regresara el viejo partido gobernante. Se hace un 
seguimiento de los votos duros o fieles y del voto independiente y se compara lo que sucedió en 2006 y 2012 para entender que el voto duro de la izquierda es muy pequeño y no le ha sido suficiente para ganar, a pesar de captar la mayoría de los sufragios independientes.

Los acercamientos que forman este conjunto muestran que hay novedades respecto de 2006 y cómo ahora se superaron varios de los obstáculos que motivaron el conflicto. Por otra parte, 2012 reactualiza problemas que no han sido resueltos. Una muy visible fue el reclamo contra la compra de votos, una expresión del modelo clientelar que se ha generalizado en la canalización de recursos para la administración de la pobreza. Esta dimensión tiene otra parte en la falta de rendición de cuentas de los gobiernos locales, dinero público vía recursos fiscales o endeudamiento, sobre lo cual se despliega la sospecha de desviación hacia las elecciones. La otra parte del problema que afecta las elecciones tiene que ver con la concentración mediática que afecta el voto informado. Si la democracia es un sistema de opinión y pluralismo, la actual estructura incide de forma directa en una manipulación de la información. Resulta paradójico que se cuide la equidad como valor a tutelar con un nuevo esquema de administración de tiempos que no logró evitar que hubiera una construcción mediática de la opción política que ganó, es decir, si la televisión no hace presidentes, sí contribuye de forma definitiva a su posicionamiento, como sucedió en esta sucesión presidencial. Una conclusión de todo este análisis es que por más que se afinen las reglas de competencia electoral y el modelo de regulación política - con múltiples factores que pueden mejorar-, si no se corrigen los temas externos de la rendición de cuentas de los gobiernos, si no se modifican las políticas clientelares de administración de la pobreza y se avanza hacia un modelo de derechos universales y si no se modifica el esquema monopólico de medios, las elecciones en México seguirán siendo un motivo de litigio y de sospecha. 